o cpod/CPOD e a experiência de cárie foram superiores aos valores amostrais. Das crianças avaliadas, $25 \%$ apresentaram níveis de cpod/CPOD muito elevados. O cpod/CPOD amostral foi 3,8 e o SIC 8,48. O índice cpod/CPOD foi comparado em função dos valores obtidos pelo perfil antropométrico, tendo sido verificado que o perfil 'excesso de peso' e 'obesidade' apresentam valores médios de cpod/CPOD superiores aos da amostra no seu todo, respetivamente 4,67 e 4. A prevalência de indivíduos com experiência de cárie da amostra é de $72,5 \%$, tendo sido verificado o valor mais alto no perfil antropométrico 'obesidade', com 91,7\%.

Conclusões: Crianças com excesso de peso e obesidade têm maior prevalência de cárie. Os fatores de proteção identificados na composição dos lanches são menos consumidos por estas crianças. Este estudo aponta fatores de proteção e de risco para desenvolvimento de cárie dentária e abre caminho a outros estudos para determinar fatores condicionantes desta patologia. Verifica-se que a educação para a saúde oral e para um estilo de vida saudável é ainda essencial na infância. http://doi.org/10.24873/j.rpemd.2017.12.165

\section{\#145 Biópsias incisionais em lesões orais potencialmente malignas: Serão fiáveis?}

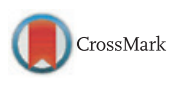

João André Correia*, Alexanda Lóio, Cecília Caldas, Paulo Palmela, António Capelo, Francisco Salvado

Serviço de Estomatologia do Centro Hospitalar Lisboa Norte, Faculdade de Medicina da UL

Objetivos: Determinar se as biópsias incisionais de Lesões Orais Potencialmente Malignas são representativas das alterações histológicas de toda a lesão; Comparar a fiabilidade de biópsias incisionais realizadas em apenas uma localização da lesão e múltiplas localizações; Identificar factores que poderão afectar a fiabilidade da biópsia incisional.

Materiais e métodos: Estudo restrospectivo incluindo os doentes com diagnóstico clínico de leucoplasia, eritroplasia e eritroleucoplasia, submetidos a biópsia incisional e posterior excisão da lesão entre Junho de 2012 e Junho de 2017, no Serviço de Estomatologia do Centro Hospitalar Lisboa Norte. Todas as análises histopatológicas foram realizadas no mesmo Centro Hospitalar. As alterações histopatológicas e diagnósticos baseados na análise da biópsia incisional foram comparados com os resultados da excisão completa. Doentes com acompanhamento inferior a 6 meses foram excluídos. A análise estatística foi realizada com IBM ${ }^{\circledR}$ SPSS $^{\circledR}$ versão 23.

Resultados: Foram incluídos 40 doentes na amostra, 21 do sexo masculino e 19 do sexo feminino, com uma idade média de $64,63 \pm 13,01$ anos. Um total de 26 lesões tiveram um diagnóstico clínico de leucoplasia, das quais 9 homogéneas e 17 não homogéneas, 10 eritroleucoplasias e 4 eritroplasias. As dimensões das lesões estavam compreendidas entre os 2,1$-4 \mathrm{~cm}$ de maior eixo em $50 \%(\mathrm{n}=20)$ dos doentes, entre os $1-2 \mathrm{~cm}$ em $37,5 \%(n=15)$ e inferiores a $1 \mathrm{~cm}$ em $12,5 \%(n=5)$. As lesões foram excisadas num tempo mediano de $80 \pm 134,68$ dias após a biópsia incisional. A concordância entre os resultados da análise histopatológica da biópsia incisional e excisão foi de $67,5 \%$ no total dos doentes e $81,8 \%$ naqueles que realizaram biópsias incisionais em múltiplas localizações da mesma lesão. Em 20\% (n=8) das lesões as alterações histopatológicas na peça de excisão foram mais graves que as da biópsia incisional sendo que $5 \%(n=2)$ corresponderam a Carcinoma Pavimento Celular e 2,5\% (n=1) a Carcinoma Verrucoso. Não foi encontrada associação com significância estatística entre a fiabilidade da biópsia incisional e tamanho da lesão, características macroscópicas, utilização de bisturi circular e tempo de excisão após biópsia.

Conclusões: As biópsias incisionais têm limitações na avaliação de Lesões Orais Potencialmente Malignas, uma vez que podem não ser representativas de toda a lesão. O acompanhamento do doente e vigilância clínica da lesão são essenciais para um diagnóstico precoce do Cancro Oral. http://doi.org/10.24873/j.rpemd.2017.12.166

\section{\#146 Enfermidades raras, doentes únicos:} A Síndrome de Stickler

M.R. Sampedro Díaz*, M.J. Filgueira Conde, A.I. Rocha, J.M. Barbas Amaral, L. Monteiro

Serviço Galego de Saúde - CESPU

Objetivos: A síndrome de Stickler é uma enfermidade genética rara do tecido conjuntivo descrita por Sticker et al. (1965). Distinguem-se vários tipos: A síndrome de Stikler de tipo 1 deve-se a mutações no gene COL11A1; a síndrome de tipo 2 a mutações no gene COL11A1 e a síndrome de tipo 3 a mutações no gene COL11A2. A transmissão da síndrome segue um modo de herança autossómica dominante, con uma forma autossómica recessiva associada a mutações nos genes COL9A1 e COL9A2. A prevalência da enfermidade não se conhece. Estimou-se que a incidência ao nascimento é de 1/7.500 a 1/9.000. Em 2001, Stickler et al. concluíram que existe uma variação muito ampla entre os diferentes sintomas e signos das pessoas afetadas, incluso dentro da mesma família. Mediante este estudo pretendemos descrever as características epidemiológicas e clínicas de um grupo de doentes com esta síndrome na Espanha, ampliando o estudo numa segunda fase a Portugal.

Materiais e métodos: A síndrome caracteriza-se por uma combinação variável de manifestações (oculares, orofaciais, ósseas, auditivas e cardíacas). As anomalias orofaciais incluem: úvula bífida, fissura palatina (ilhado ou na sequência de Pierre Robin), hipoplasia malar e microrretrognatia. As anomalias ósseas de ATM descritas são artrose precoce secundária a uma hiperlassitude infantil. Realizou-se revisão bibliográfica Pubmed (1965-2017), sem achar estudos que indicaram percentagens de afetação orofacial. Solicitamos a colaboração da Asociación Española de Stickler (50 sócios e famílias). Realizamos um estudo descritivo recorrendo aos dados médicos de 35 doentes com diagnóstico clínico confirmado.

Resultados: Dos 35, 20 (57,14\%) eram homens e 15 (42,86\%) mulheres. A idade média foi 20 anos (4-60). As manifestações orais encontradas foram: Fissura palatina: 6 (17,65\%), palatal ogival: 8 (23,53\%), fissura palatina palatal ogival: $10(29,415)$, nenhuma alteração palatal 12 (35,29\%). Micrognatia: 18 (52,94\%). Glosoptise: 8 (23,53\%). Sequência de Pierre Robin: 9 
(26,47\%). Hipoplasia malar: 22 (64,71\%). Agenesias dentárias: 6 (17,65\%). Refluxo gastroesofágico: 6 (17,65\%). Afetação ATM: 15 (50\%), sendo artrose dor: $3(8,82 \%)$, artrose sem dor: $1(2,94 \%)$, dor sem artrose: 11 (32,35\%).

Conclusões: Este estudo retrospetivo permite-nos quantificar e caraterizar as manifestações orais de doentes com Stickler num estudo pioneiro em simultâneo com a realização de um censo da enfermidade na Espanha e em Portugal, alargando o estudo para os centros portugueses que tratan esta patología

http://doi.org/10.24873/j.rpemd.2017.12.167

\#147 Oncologia Oral: mucosite oral e o seu impacto no doente oncológico

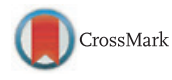

Jennifer Monteiro*, Augusta Silveira, Teresa Sequeira

Universidade Fernando Pessoa

Objetivos: Discutir os impactos da mucosite oral (MO) na sobrevivência e QdVRS em oncologia oral. Apresentar as normas recomendadas internacionalmente para actuar na MO.

Materiais e métodos: Revisão sistemática da literatura (2007-2017).

Resultados: A MO surge frequentemente associada à ulceração, sangramento e predisposição para infeção oral - os sinais e sintomas frequentemente se associam à má nutrição, internamento e interrupção no tratamento oncológico. A prevenção e o tratamento apoiam-se em recomendações/sugestões a favor e contra uma intervenção. O protocolo de cuidados orais, suplementos de zinco, crioterapia (30 minutos) e terapia com laser de baixa intensidade $(650 \mathrm{~nm})$ são sugeridos. No tratamento da dor, o uso de fentanil transdérmico, bochehos com soluções de morfina a 0,2\%, doxepina a 0,5\% ou benzidamina podem ser úteis. Os bochechos com soluções de sucralfato ou clorohexidina e a administração de pilocarpina não estão recomendados.

Conclusões: Uma adequada abordagem médica frente à MO tem como resultados um aumento da sobrevivência e uma optimização da QdVRS.

http://doi.org/10.24873/j.rpemd.2017.12.168

\#149 Relação entre o ângulo funcional mastigatório e o lado preferencial de mastigação

CrossMark

Iryna Fediv*, Ana Carvalho, Luís Silva, Patricia Fonseca

Instituto de Ciências da Saúde da Universidade Católica Portuguesa - Viseu, Centro de Investigação Interdisciplinar em Saúde da Universidade Católica Portuguesa

Objetivos: Os principais objetivos desta investigação são: 1- Identificar o ângulo funcional mastigatório; 2- Identificar o lado preferencial de mastigação; 3- Determinar a relação entre ambos.

Materiais e métodos: Foram avaliados 70 indivíduos (58,6\% mulheres; 41,4\% homens), 51 (72,9\%) da Clínica Universitária do Instituto de Ciências da Saúde da Universidade Católica Portuguesa e 19 (27,1\%) da Policlínica do Sátão. A medição do ângulo funcional mastigatório foi efetuada com um ortómetro, transferidor e régua milimétrica, registando-se a amplitude do ângulo formado na linha média pela interceção da trajetória seguida pelo incisivo central inferior no movimento de lateralidade em relação a um plano horizontal de referência, paralelo ao plano oclusal. Através do teste da pastilha elástica determinamos o lado preferencial de mastigação inicial e o lado de mastigação continuada (10 ciclos), registando-se como predominantemente unilateral direita, unilateral esquerda ou bilateral. Todos os procedimentos éticos e legais foram respeitados e os dados recolhidos foram introduzidos e analisados no software IBM SPSS Statistics ${ }^{\circledR}$ (versão 24) considerando um nível de significância de 5\% na inferência estatística.

Resultados: No que diz respeito ao ângulo funcional mastigatório, 47,1\% ( $\mathrm{n}=33)$ dos pacientes apresentam (à direita e à esquerda) ângulos iguais ou semelhantes; 34,3\% (n=24) têm o ângulo funcional mastigatório superior à esquerda e 18,6\% $(n=13)$ superior à direita. Dos 70 pacientes avaliados, 22,9\% $(\mathrm{n}=16)$ não apresentam um lado preferencial de mastigação, $28,6 \%(n=20)$ mastigam preferencialmente à esquerda e 48,6\% $(\mathrm{n}=34)$ mastigam preferencialmente à direita. Encontramos uma relação estatisticamente significativa entre o ângulo funcional mastigatório e o lado preferencial de mastigação ( $\mathrm{p}<=$ $0,05)$. Se o ângulo funcional mastigatório for diferente, a mastigação é preferencialmente unilateral para o lado de menor ângulo.

Conclusões: Uma vez que a maior parte dos pacientes não reconhece o seu lado preferencial de mastigação e que o mesmo tem repercussões funcionais importantes que podem afetar todos os componentes do sistema estomatognático (músculos, ossos, articulação, dentes e periodonto) e consequentemente comprometer uma reabilitação oral, clinicamente é importante que a existência de uma relação entre o ângulo funcional mastigatório e o lado preferencial de mastigação tenha sido provada.

http://doi.org/10.24873/j.rpemd.2017.12.169

\#150 Associação entre o Cronotipo e o Bruxismo Auto-Referido - Estudo entre Portugal e Brasil

Diana de Sousa*, Ricardo Dias, Maria João Rodrigues

Faculdade de Medicina da Universidade de Coimbra

Objetivos: Cada indivíduo tem um perfil e um relógio biológico de sono específico e individualizado definido como cronotipo. O bruxismo é definido como uma parafunção da musculatura mastigatória, que culmina no apertar e ranger de dentes e/ou na contratura da musculatura sem os dentes estarem necessáriamente em contacto. Tem uma etiologia multifatorial, mediada centralmente e onde intervêem e interagem fatores fisiopatológicos, morfológicos e psicossociais. Entre os fatores fisiopatológicos incluem-se as perturbações do sono. O conhecimento e a modificação do cronotipo pode mediar e contribuir para um prognóstico mais favorável no controlo e prevenção de determinadas patologias. Deste modo, o objetivo principal deste trabalho é verificar a possível relação entre bruxismo auto-referido e cronotipo. 